\title{
Editorial: The Straw and the Camel
}

'Credit for the quality of the articles must go principally to the contributors.' This humane sentence is buried deep in the Preface to the Encyclopedia of Bioethics. Without such reassurance a careful reader of the forty pages of prolegomena might suspect that the work followed the trend set by the Fiat Strada, 'hand-made by robots'. Inspection procedures on the assembly line were kept to the highest modern standards:

To assure accuracy of content, articles in this encyclopedia were subject to review not only by the editors but by specialists in the numerous fields of learning discussed by the articles. More than 300 special reviewers were called upon to examine manuscripts for accuracy and comprehensiveness, and, on occasion, to recommend alternate authors and reviewers. These reviewers represent fields as diversified as surgery, Islamic studies, pediatrics, philosophy, environmental sciences, theology, psychiatry, philosophy, law, public health, anthropology of medicine, geriatrics, policy studies, genetics, history, psychology, demography, and health-care administration.

The flattering double entry for philosophy must not charm us out of a duly questioning posture. Do we need an Encyclopedia of Bioethics? If so, can we afford to live without an Encyclopedia of Aesthetics, an Encyclopedia of Philosophical Theology, and a Dictionary of Legal Philosophy? What about the Philosophy of the History of Science and the History of the Philosophy of Science? Already there are journals devoted to Metaphilosophy, the Teaching of Philosophy, and Philosophy and Public Affairs. Why not a Yin-yang Yearbook, or an Archive of Advances in Anaxagorean Studies? The Philosophy Documentation Center at Bowling Green, Ohio might find some new challenges invigorating. The Society of Philosophy Journal Editors, at its quarterly conference in Fiji or Bermuda, could have an agenda weighty enough to distract it from its preoccupation with the design and development of a Metasociety of Associations of Ancillary Adjuncts to the People who Actually Think and Act.

It would be unfair to the Encyclopedia of Bioethics to treat it as specially deserving the doubts and suspicions that its arrival may evoke. The judicious camel, seeking to account for a broken back, must spread the burden of responsibility among the straws. It is not the fault of Warren $T$. Reich (the Editor in Chief) or the Joseph and Rose Kennedy Institute of Ethics at Georgetown University (the sponsor) or Macmillan and Free Press (who publish the four volumes and 1900 pages at a price of $\$ 200$ ) 


\section{Editorial}

that the big business of publishing is more and more conducted like Big Business, and that the products of the industry of philosophers and other scholars are increasingly presented and promoted as if they were industrial products. Besides, when we come to the articles themselves (Abortion, Acting and Refraining, Adolescents, Alcohol, Animal Experimentation, Death, Dentistry, Double Effect, Pain and Suffering, Pragmatism, Privacy, Protestantism, Sexual Ethics, Smoking, Suicide) we find them serious, sometimes stimulating, occasionally well written, and nearly all provided with useful bibliographies. Yet the doubts remain, and some of the best articles reinforce them. Sydney Shoemaker on the Mind-Body Problem, Antony Flew on Evolution and R. M. Hare on Utilitarianism are likely to be worth reading in any context, but some contexts are more appropriate than others. Readers who are primarily concerned with philosophy know where else to find abundant material on these themes, and it is not clear that the clients for whom the Encyclopedia is chiefly intended-medical students and practitioners, nurses, lawyers, social workers, journalists, politicians - will either want or need to be led into any of the more academic controversies of philosophy.

But the Encyclopedia of Bioethics deserves to be used, and it will be used, because it is there, even if, as we turn its pages, we wonder why they are so numerous, and overlap so widely with those of so many other works. As readers we acknowledge complicity in the making of many books, a complicity like that of the driver who complains of the overcrowding on the motorways or the traveller who feels that the hills and valleys, cities and galleries, would be all the more exhilarating if they were not infested with tourists. 